\title{
Application Status and Trend of "Internet Plus" Modern Agriculture in China and Abroad
}

\author{
Zhao Chunjiang $^{1,2,3,4}$, Li Jin ${ }^{1,2,3,4}$, Feng Xian ${ }^{1,2,3,4}$, Guo Meirong ${ }^{1,2,3,4}$ \\ 1. Beijing Research Center for Information Technology in Agriculture, Beijing 100097, China \\ 2. National Engineering Research Center for Information Technology in Agriculture, Beijing 100097, China \\ 3. Key Laboratory of Agri-informatics, Ministry of Agriculture, Beijing 100097, China \\ 4. Beijing Engineering Research Center of Agricultural Internet of Things, Beijing 100097, China
}

\begin{abstract}
Internet Plus" provides new methods for agricultural and rural modernization, and it is an important starting point of and foothold for the development of modern agriculture in China. Summarizing the domestic and foreign "Internet Plus" modern agricultural development policies and industrial strategic landscapes, this study analyzes the application status of various technologies. These technologies include the "Internet Plus" modern agriculture-embodied large-scale networked application of agriculture in large farms in the United States; integrated agricultural information and intelligent technologies applied to smart precision agricultural equipment in Germany; fine-scale production of smart agricultural machinery in Japan; and high-speed broadband network-based, high-efficiency eco-agriculture in Australia. Additionally, this study analyzes domestic applications such as field planting, facility agriculture, aquaculture, livestock and poultry breeding, and seed industry in China. This study also highlights the development trend of "Internet Plus" modern agriculture in bioinformatics, artificial intelligence, plant protection of drones, and the development and application of smart, connected products.
\end{abstract}

Keywords: Internet Plus; modern agriculture; application status; development trend

\section{Introduction}

Emerging technologies represented by the Internet of Things (IoT), big data, and artificial intelligence are guiding the agricultural industry to the middle and high-end markets. In July 2015, the State Council released Opinions of the State Council on the Positive Promotion of the "Internet Plus" Action, which was viewed as one of 11 important strategic actions. "Internet plus Agriculture" refers to practices reflecting the concept, technologies, and methods of the Internet in agriculture. These practices can not only effectively improve agricultural quality, effectiveness, and competitiveness but also realize the transformation from traditional to modern agriculture.
Currently, positive progress has been made through the Internet and agriculture-integrated innovations throughout the world. Large-scale farms in America have assumed the main force for application of agricultural IoT. Japan is devoted to the development of precision agriculture for appropriately scaled farms. Australia is making significant efforts to develop high-efficiency ecological agriculture based on the construction of a high-speed broadband network. The modernization of agriculture in China is faced with unprecedented opportunities and challenges. China requires advanced technologies to enhance agricultural productivity and achieve leapfrog development in agriculture. In 2015, the Chinese Academy of Engineering set up the key " Internet Plus' Development Strategic Study” consulting project and en-

Received date: March 22, 2018; Revised date: March 28, 2018

Corresponding author: Li Jin, Beijing Research Center for Information Technology in Agriculture, Researcher. Major research field is agricultural and rural informatization. E-mail: lij@nercita.org.cn

Funding program: CAE Advisory Project “Development Strategy of 'Internet Plus' Action Plan”(2016-ZD-03)

Chinese version: Strategic Study of CAE 2018, 20 (2): 050-056

Cited item: Zhao Chunjiang et al. Application Status and Trend of "Internet Plus" Modern Agriculture in China and Abroad. Strategic Study of CAE, https://doi. org/10.15302/J-SSCAE-2018.02.008 
listed research on the "Internet Plus" modern agricultural development strategy into project topics. Based on a thorough review of the status of agricultural information technology, industry, and applications throughout the world, the conceptual connotation of "Internet Plus" modern agriculture was proposed. "Internet Plus" modern agriculture involves constructing an intelligent agricultural service cloud centered on "producers-processorsdealers-consumers" and based on a ubiquitous network, with the help of new-generation information technologies such as mobile Internet, IoT, cloud computing, big data, and intelligent manufacturing, and mass agricultural data. These technologies are used for the automatic perception, accurate recognition, and intelligent control of humans, machines, objects, the environment, and information in the agricultural industry chain, thus forming the agricultural 4.0 industrial form characterized by intelligent production, traceable circulation, platform transaction, and customized service. Through this project, the strategic goals, tasks, key technologies, roadmaps, and key projects of the "Internet Plus" modern agricultural development for 2020, 2025, and 2035 were proposed. In this study, the current strategic layout, application status, and development trend of "Internet Plus" modern agriculture at home and abroad are analyzed. The results can provide China with references for formulating an agricultural informatization development strategy.

\section{Strategic layout of "Internet Plus" modern agriculture at home and abroad}

\subsection{Policy layout}

In recent years, many countries have viewed the development of "Internet Plus" modern agriculture as a priority development strategy for their agricultural construction and have released a series of key strategic measures (Table 1). In 2013, the U.K. government released the Agricultural Technological Strategy, which adopted the construction of agricultural information technology and sustainable development index center as the basis for the strategy to be implemented. The strategy emphasized that the U.K. would concentrate investments in agricultural technologies on big data and commit to realizing the commercialization of agricultural technologies and development of an agricultural information power throughout the world. In 2012, the European Union (EN) released the Information Technology and Agricultural Strategic Research Roadmap to develop precision agriculture and livestock industries through a farm management information system (FMIS) and to prioritize agricultural informatization technologies such as automatic indoor environmental controls, automatic agricultural product quality controls, and agricultural robots to improve agricultural management efficiency. In 2015, Japan issued a new robot strategy, which proposed the launch of the "next generation of agriculture, forestry, and aquaculture creative technology" based on the Intelligent Machine Plus IT [1]. In 2016, Japan in- vested 4 billion yen and developed 20 types of robots to promote farm automation. The United States launched network and information technology special series research plans, which covered key fields, such as robot technology, advanced manufacturing technology, and biological monitoring. These plans realized the socialization of sharing of agricultural data resources using automatic control technology and network technologies. In 2012, the American government announced the Big Data Research Development Plan, which was worth $\$ 200$ million. This plan recommended accelerating scientific and engineering research and strengthening national security by improving the ability to extract knowledge and opinions from complicated big data.

The integration of information technology and modern agriculture in China has attracted a lot of attention from the government since the first proposal for the construction of agricultural informatization appeared in 2005 in the Central Document No. 1 and corresponding strategic plans were released. The Opinions of the State Council on the Positive Promotion of the "Internet Plus" Action (State [2015] Document No. 40) proposed the strategic deployment of an "Internet Plus" modern agriculture. The vigorous implementation of an "Internet Plus" modern agricultural action was proposed in many subsequent documents such as the Opinions on Promoting the Integrated Development of the Primary, Secondary and Tertiary Industries in Rural Areas (National Office [2015] Document No. 93), Implementation Scheme of Three-year Action for Internet Plus Modern Agriculture (Agricultural Department [2016] Document No. 2), National Agricultural and Rural Informatization Development Plan During the 13th Five-Year Plan(Agricultural Department [2016] Document No. 5), and Opinions of the State Council and the CPC Central Committee on Deepening Structural Reform at the Agricultural Supply Side and Accelerating Development of New Momentums for Agricultural and Rural Development (China [2017] Document No. 1). Among them, the Implementation Scheme of Three-year Action for Internet Plus Modern Agriculture pointed out that in 2018, the integrated development of Internet and agriculture, rural areas, and rural residents as well as the online and data-intensive development of agriculture will achieve significant progress. Basically, high-efficiency management and service convenience will be realized. Production intelligence and management networks will step into a new stage. The urban-rural digital gap will shrink further. Basically, a popular entrepreneurial situation will be formed and support for agricultural modernization will considerably increase. The reports of the 19th National Congress of the Communist Party of China in October 2017 proposed the implementation of a rural revitalization strategy and emphasized the promotion of the deep integration of the Internet, big data, artificial intelligence, and a substantial economy. In addition, China has engaged in a corresponding deployment of agricultural big data and agricultural e-commerce. Thus, the top layer of "Internet Plus" modern agriculture has been preliminarily formed. 
Table 1. Strategic planning of "Internet Plus" modern agriculture at home and abroad.

\begin{tabular}{|c|c|c|}
\hline Countries & Strategic documents & Strategic goals \\
\hline Germany & Industry 4.0 Strategic Proposal & $\begin{array}{l}\text { Implement intelligent manufacturing, including agricultural equipment, as an } \\
\text { adaptation to the "Internet Plus" development trend. }\end{array}$ \\
\hline Korea & Information Network Village Plan & $\begin{array}{l}\text { Develop and use information resources and accelerate the promotion of rural } \\
\text { informatization construction to shrink the urban-rural gap and increase farmers' } \\
\text { income levels. }\end{array}$ \\
\hline \multirow[t]{2}{*}{ Japan } & Japan's Robot Strategy & $\begin{array}{l}\text { Construct the "next generation of creative technologies for agriculture, forestry, and } \\
\text { aquaculture" based on intelligent machine Plus IT. }\end{array}$ \\
\hline & Agricultural and Rural Informatization Strategy & Narrow the urban-rural gap in informatization and vitalize the country. \\
\hline UK & A UK Strategy for Agricultural Technologies & Agricultural information power throughout the world \\
\hline France & Intelligent County Action & $\begin{array}{l}\text { Guide and inspire the public to accept new information technology and train the } \\
\text { public and some associations and professionals in rural areas to create Internet stations } \\
\text { that are open to the public year-round using new technologies and office tools. }\end{array}$ \\
\hline $\mathrm{EU}$ & $\begin{array}{l}\text { Information Technology and Agricultural } \\
\text { Strategic Research Roadmap }\end{array}$ & $\begin{array}{l}\text { Construct a farm management information system (FMIS) and realize precision } \\
\text { production in the plantation and livestock industry using automatic indoor } \\
\text { environmental controls, automatic quality controls, and agricultural robots. }\end{array}$ \\
\hline USA & Big Data Research Development Plan & $\begin{array}{l}\text { Enhance America's ability to extract knowledge and opinions from complicated big } \\
\text { data. }\end{array}$ \\
\hline India & National Information Technology Policy System & $\begin{array}{l}\text { Construct a "global information technology superpower" and "pioneer of the } \\
\text { information revolution era." }\end{array}$ \\
\hline \multirow[t]{3}{*}{ China } & $\begin{array}{l}\text { Implementation Scheme of Three-year Action for } \\
\text { Internet Plus Modern Agriculture }\end{array}$ & $\begin{array}{l}\text { The integrated development of the Internet and "agriculture, rural areas, and rural } \\
\text { residents" will achieve outstanding fruition in } 2018 \text {. }\end{array}$ \\
\hline & $\begin{array}{l}\text { National Agricultural and Rural Informatization } \\
\text { Development Plan During the 13th Five-Year } \\
\text { Plan }\end{array}$ & $\begin{array}{l}\text { By } 2020 \text {, the "Internet Plus" modern agricultural construction will achieve outstanding } \\
\text { progress. The application proportions of information technologies (e.g., agricultural } \\
\text { IoT) will reach } 17 \% \text {, and the proportion of online retail sales of agricultural products } \\
\text { as a part of gross agricultural output will reach } 8 \% \text {. The coverage of information } \\
\text { service stations in rural areas will reach } 80 \% \text {, and Internet penetration in rural areas } \\
\text { will reach } 52 \% \text {. }\end{array}$ \\
\hline & $\begin{array}{l}\text { The 13th Five-Year Plan for Economic and } \\
\text { Social Development of People's Republic of } \\
\text { China }\end{array}$ & $\begin{array}{l}\text { Develop intelligent agriculture and increase agricultural technological equipment and } \\
\text { the informatization level. }\end{array}$ \\
\hline
\end{tabular}

\subsection{Industrial layout}

As viewed from the industrial layout strategy, international agricultural giants successively implement the global industrial layout of the "Internet Plus modern agriculture," which hastens the development of a batch of strategic emerging industries, such as agricultural big data, intelligent agricultural equipment, and agricultural IoT, accompanied by increasing enterprise mergers and acquisitions and venture capital transactions.

In October 2013, Monsanto acquired the Climate Corporation for $\$ 930$ million. In May 2014, DuPont Pioneer and AGCO Equipment agreed to cooperate to implement a seamless interface for a farmland decision service platform and an interface for data transfer and farmland management information using AGCO equipment. They assisted farmers in improving output and profits using big data management and mining as well as precision marketing and delivery. This cooperation symbolized the entry of agricultural big data into a substantial promotional stage. In September 2017, John Diehl from the American Agricultural Machinery Company acquired the artificial intelligence pioneer Blue River for \$305 million, signaling that the agricultural machinery giants' had started paying significant attention to artificial intelligence R\&D. The agricultural field was now going to be "intelligent."

With respect to agricultural machines and unmanned aerial vehicles (UAVs), more than 2500 Yamaha crop protection UAVs were used in Japan in 2015, and the rice fields that used Yamaha UAVs for spraying pesticides accounted for 35\% to $40 \%$ of the country's total field area. In the same year, Yamaha (Japan) entered into the American market and became the first company approved by the U.S. government to market UAVs that sprayed agricultural pesticide. In 2016, CLAAS, a Germany husbandry machine and agricultural vehicle manufacturer, cooperated with Deutsche Telekom to strengthen communication among machines using sensor technology and "industry 4.0 technology." The cooperative effort realized full automation and informatization of the entire harvest process and guided the development of top precision agricultural technology based on the fourth-generation mobile communication technology, cloud safety technology, and big data analysis technology.

Internet-based thinking is enabling a comprehensive deconstruction and remodeling of the agricultural industrial chain in China. From agricultural production data marketing, information intermediary services, and land transfers to agricultural produc- 
tion and agricultural product marketing, the Internet giants and new agricultural business entities that possess Internet-based thinking have taken the initiative in all links of the agricultural industrial chain and in the exploration of new modes of agricultural business. Shenzhen Batian Ecotypic Engineering Co., Ltd., a compound fertilizer R\&D production enterprise in China, bought the stock of Beijing Jinhe Tiancheng Science and Technology Ltd., an agricultural informatization enterprise, and engages in deep cooperation with e-commerce platforms (e.g., rural Taobao and Jingdong) for online-offline integrated management. By exploring Internet Plus in agricultural plantations, the company paid attention to fertilizer production and marketing and took control over rare resources in the industrial chain, thereby constructing a running platform of ecological and intelligent agriculture. LOVOL, a leading agricultural mechanized equipment manufacturer in China, makes full use of "Internet Plus" thinking to deeply integrate the manufacturing industry and informatization. LOVOL successively constructed the ARBOS intelligent agricultural solution, an agricultural machine information service center, and the $\mathrm{C} 2 \mathrm{C}$ agricultural machine intelligence service platform [2] and realized the updating of agricultural equipment from a manufacturing to intelligence level and then to the smart level.

\section{Application status}

\subsection{Application status in foreign countries}

The deep integration of agriculture and the Internet is an important force for reform to solve multiple constraints in areas such as population, resources, environment, and market that current agricultural development faces, reconstruct the pattern of agricultural development, and energize rural development. Therefore, many countries, including the United States, Germany, and Australia, view "Internet Plus" modern agricultural technologies, industries, and applications as important to increasing their country's agricultural competitiveness and have included them on the national modernization agenda. These countries have achieved a series of technological breakthroughs and brought a batch of application examples.

Large-scale farms in America have become leaders in the application of agricultural IoT. Based on the developed agricultural network system, $69.6 \%$ of farms in America collect data using sensors and implement agriculture-related business activities. Agricultural robots have been applied to agricultural production activities such as sowing, pesticide spraying, and harvesting. In farm management, farmer households have real-time information on soil structure, growth rates, irrigation and fertilization, farming logs, pest and disease damage, environmental meteorological information (including precipitation, sunshine air temperature records, and heat accumulation), and a farm's estimated investments and output using the Internet and mobile
Internet. The Internet and mobile Internet are also conducive for yield forecasting, profit estimation, and inventory management, thereby improving the scientific management of farms [3]. In 2015, by analyzing precision agricultural technological applications, America discovered that the fastest growth rate was UAV plant protection technology [4] and the intelligent agricultural equipment market is being preliminarily formed, indicating that America has taken the lead in intelligent agricultural equipment.

Germany developed independent technological advantages by achieving breakthroughs in key technologies related to agricultural informatization and the intelligent agricultural field. The country's breakthroughs started from the computer registration of every land type and the value and construction of an information system for villages and roads and then continued with the application of assistant decision-making technologies for comprehensive crop management and construction of the current perfect agricultural information-processing system [5]. The German government pays significant attention to the construction of public platforms. In particular, breeding informatization platforms, breeding of new varieties, new cultivation technologies, excellent techniques for livestock reproduction, and pest control technology have been popularized to farmer household enterprises. Through indoor automatic computer control, large agricultural machines equipped with the " $3 \mathrm{~S}$ " technology can perform various farmland operations and accomplish multiple functions, such as precision sowing, fertilization, weeding, harvesting, precise feeding of livestock, digital milking of cows, among others [6]. Furthermore, these machines can realize vector fertilization and pest spraying at different places on the same land, thereby assuring high-efficiency utilization of pesticide and fertilizers without causing environmental pollution [7].

To solve the limitations of a large population with relatively little land, Japan took the initiative to develop an appropriately scaled, refined agricultural production mode and simultaneously designed portable intelligent agricultural machines [8], monitored crop yield using UAVs [9], strengthened the cooperation between agricultural operation subjects and information technology suppliers, and promoted the popularization and application of precision agricultural technologies. Currently, more than 50\% of the farmer households in Japan have applied agricultural IoT technologies to agricultural production. Japan has become a representative of precision agricultural development throughout the world.

Based on high-speed broadband network construction, Australia integrated Internet technology into its rural economic and social development and developed an ecological agriculture using modern information technology. The National Information and Communication Technology Association of Australia studied and developed various intelligent applications that farmers find convenient for use through the Farmnet platform, which can be downloaded by farmers for free. The Agricultural and Resource Economic Services Bureau of Australia constructed an agricul- 
tural comprehensive information service platform that comprises a monitoring information system, a prediction system, and an agricultural product information system. Information on the platform is free, which realized high-efficiency sharing among multiple departments [10]. In addition, the "multi-case analysis system (MCAS-S)" can help relevant departments in assessment and decision-making.

Based on the development of competitive IT industries, the Government of India positively promoted the development of electronic agriculture, constructed several professional agricultural information database systems, and provided farmer multiform and all-round information services to farmers using Internet platforms [11]. The e-commerce sales volume of agricultural products accounted for $60 \%$ of the national e-commerce trade volume, which was significantly higher than in many developed European and American countries. Currently, the network transaction platform of agricultural products in India covers 36,000 villages in nine states. Approximately 3.5 million Indian farmers sell agricultural products through network transaction platforms. The agricultural market information system and the price prediction system have become informatization service systems that are widely used in Indian agriculture [12]. The market price of agricultural products is predicted by an economic model and the risk caused by price fluctuations is reduced. With a perfect network infrastructure, developed countries such as the United States, the United Kingdom, and Japan have developed multiple Internet modes of perpendicular network applications and technological services, including digital content suppliers, preparation and delivery, door-to-door delivery of fresh foods, online booking, next-generation POS systems, and next-generation purchase platforms.

\subsection{Application status in China}

Since the implementation of regional-applied demonstration projects of agricultural IoT in China in 2013, "Internet Plus" modern agriculture has been increasingly used in a series of key technological agricultural informatization products and equipment such as field plantation, facility agriculture, aquaculture, livestock breeding, and the seed industry. A batch of technological application modes is practiced, and outstanding effects supporting modern agricultural development are achieved.

The quantity and quality of agriculture-related service platforms are continuously increasing. Currently, China has formed several government-dominated agricultural and rural comprehensive information service platforms (e.g., Jin Nong Project, 12316 comprehensive information service agricultural platforms of rural areas and rural residents, and safe tracing platforms for agricultural product quality) and many professional market-oriented agriculture-related service platforms (e.g., Lvyunge, Jiage satellite remote sensing big data platform, and Breaker China agricultural big data platform). These platforms can provide various services to different objects and application subjects, including government information, practical technologies, market information, alarming information, and production data.

With respect to "Internet Plus" field plantations, the Internet and IoT have achieved significant breakthroughs and are extensively used in cultivating soil preparation, "four-situation" monitoring of crops, precision application of water, fertilization, and pesticides in farmland, agricultural aviation crop protection, and agricultural machine management and scheduling. The Xinjiang production and construction corps pilot set up a comprehensive IoT platform for the field production of cotton, which integrated automatic control of field drop irrigation, automatic monitoring of pump efficiency, automatic forecasting of soil moisture content, field meteorological environmental monitoring, and smartphone-based remote control [13]. This platform increased the per capita management quota from 50 acres to 300 acres. Moreover, water and electricity savings increased by more than $10 \%$ and $40 \%$, respectively, and crop yield increased by more than $8 \%$. The average efficiency growth per acre was approximately 210 yuan/acre.

For "Internet Plus" agricultural facilities, full monitoring and management of agricultural production based on intelligent monitoring, data acquisition, remote transmission, intelligent analysis, and automatic control is an effective path for facility production and standardized management in China. Such production has been widely used in the suburbs of metropolises, especially water-fertilizer integration and environmental monitoring control. Tianjin Da Shun International Flower Co., Ltd. realized automatic, intelligent, scaled, and standardized flow production through greenhouse environment control systems, tide irrigation systems, automatic hierarchical systems, and automatic transportation and package systems. The daily manager population in a $300000-\mathrm{m}^{2}$ greenhouse decreased from 450 to 90 , which saves annual manpower costs of more than 1 million yuan [14].

Information technologies and equipment, including real-time water environmental monitoring, automatic precision feeding, disease monitoring and early warning of aquatic products, circulation water equipment control, and net cage lift control have been promoted in "Internet Plus" aquaculture [15]. Consequently, aquaculture equipment engineering, technological precision, production intensification, and management intelligence levels were significantly improved. The aquaculture intelligent management system in the Fengxian District (Shanghai), the myriad aquaculture IoT intelligent control management system in Wuxi City (Jiangsu Province), and the "IoT-based seawater industrial aquaculture environmental monitoring and control" of Tianjin Haifa Treasure Industrial Co., Ltd. have witnessed effective growth in economic benefits and aquaculture product quality.

Real-time environmental monitoring, digital production records, intelligent logistics management, and quality tracing platform are extensively used in the "Internet Plus" livestock industry [16]. Anhui Haoxiang Agricultural and Animal Hus- 
bandry Co., Ltd. applied the production management system at a pig farm, breeding environmental monitoring system and pig epidemic control system, which improved the breeding environment, reduced breeding risk and resource consumption, and greatly increased economic benefits. This production mode can save two-thirds of staffing under the same feeding amount, and it increased the per capita daily feeding from 400 animals to 1200 animals, the batch survival rate from $95.6 \%$ to $96.85 \%$, and pig prices by a third.

Regarding "Internet Plus" breeding, in January 2016, the National Agriculture Information Engineering Technology Research Center launched the "Gold Seed Breeding Cloud Platform" with independent intellectual property rights. The platform integrated information technologies (e.g., IoT) and commercial breeding technologies and combined application computers, geographic information systems, and artificial intelligence for informatization management from parent selection to a variety of breeding based on acquisition, processing, statistical analysis and the comprehensive evaluation of field breeding material character data. The effort realized integrated innovations of modern information technologies (e.g., big data and IoT) and traditional breeding technologies. This platform has been successfully used in large breeding enterprises such as the Shandong Shengfeng Seed Industry Scientific and Technological Co., Ltd. and Hunan Longping High-tech Agriculture Co., Ltd., comprehensive crop pilot stations (e.g., National Rice Pilot Station of Hunan Yueyang Agricultural Science Research Institute), research units, and mid- and small-sized breeding enterprises (e.g., Tianjin Academy of Agricultural Sciences and China Agricultural Seed Industry).

With regard to "Internet Plus" agricultural product quality safety tracing, automatic recognition technology, sensor technology, mobile communication technology, intelligent decision technology, and IoT are being continuously developed, which lays the foundation for full supply chain tracing systems for agricultural products and foods that integrates comprehensive perception, real-time transmission, and intelligent decision-making [17]. Currently, this system not only realizes tracing of the entire industrial chain as well as pre-prompt, in-process early warning, and post detection of organic production but also achieves agricultural products tracing based on different characteristics of vegetables, fruits, livestock, and aquatic products. As a result, some application examples are available, such as the Tianjin Cabbage Base Management System and the Guangzhou Quality Safety Tracing Management Platform of Agricultural Products.

Regarding e-commerce for agricultural products, many fresh food platforms are being continuously launched, which has hastened the development of a number of vertical e-commerce entities (e.g., Ali, large Jingdong fresh food platforms, the Womai website, and daily high-quality fresh products of SF Express), O2O platforms (e.g., Baidu take-out, Meituan, and Eleme), and e-businesses [18]. These platforms meet people's increasing demand for fresh food. Tianjin has supported the development of many local e-commerce enterprises (including Shi Guan Jia, Jin Nong Bao, You Nong Le Xuan, and Wang Tong E-Commerce), as well as a group of online agricultural product transaction application pilots (including agricultural products of Ji County, Ji Feng Vegetables, and Beicheng Double-street E-commerce Village) that have realized full-process services from online purchase, logistics distribution, and electronic payment.

\section{Development trends}

With the continuous development of scientific technologies, the integration of new technologies, new concepts, and agriculture have continuously deepened, and modern agriculture will embrace profound development reforms in the future. The following development trends have been observed.

\subsection{The agricultural network infrastructure construction in rural areas will become more perfect.}

Internet will be further popularized in rural areas. Rural broadband infrastructure is further perfected, and high-speed broadband almost covers all rural families. The running speed of $4 \mathrm{G}$ networks will increase, and the cost will reduce. Besides, smartphones, wireless equipment, and other mobile terminals have been extensively used in rural areas. 5G technology and network applications have become increasingly mature. The virtual net and mobile devices will be integrated with artificial intelligence and automatic driving. In the next five to ten years, mobile Internet will become the mainstream of the network infrastructure in rural areas, with the increasing development of mobile Internet technologies, popular and convenient telecommunication services, and popularization of high-quality, simple, and inexpensive rural mobile terminals. The mobile Internet will provide important support for creating modern intelligent rural areas.

\subsection{New technological reforms such as bioinformatics, artificial intelligence, and UAV will subvert the traditional agricultural development mode}

Given the rapid development of high-flux plant-phenotypemeasuring technology, artificial intelligence, and sensors, information technology will be further integrated with genomics, bioinformatics, big data, and control technologies. The crop genotype-environment-phenotype relationship has been thoroughly analyzed using new technologies such as agricultural remote sensing, data modeling, and omics analysis. The results can not only support the systematic elaboration of the formation law for crop phenotype and gene and environmental regulation mechanisms as well as the construction of a high-efficiency precision molecular breeding system but also protects the safe and effective supply of agricultural products. Artificial intelligence 
technology has become the mainstay of scientific and technological circles. A series of equipment and products with independent property rights, such as agricultural intelligent robots, small portable intelligent agricultural machines, and intelligent speech recognition systems, will be used more in the full agricultural industrial chain and will significantly increase labor productivity and resource utilization. UAV crop protection integrates control, navigation, and communication technologies and forms an automatic operation technological system. Intelligent operation mode and intelligent management based on UAV crop protection can save significant labor and better protect the field ecological environment.

\subsection{Internet marketing trend of agricultural products will be more prominent}

Given the expanding population of Internet technologies and the rise of an emerging middle-class consumer group, the agricultural product marketing network will improve and present the trends of full-channel integration, cross-border e-commerce, and industrial ecological integration. The innovative mode that uses new agricultural management subjects as the new force and e-commerce as the mainstream industrial state will become an important starting point for the modern agricultural development of "Internet Plus" in China. These changes can drive the transformation of non-standardized agricultural products into a modern "informatization," "standardization," and "branding" circulation market of agricultural products.

\subsection{Agricultural big data will provide modern agriculture with online, individualized, and precise information service}

The depth and breadth of the applications for agricultural big data will continuously be extended. Intelligent informationprocessing tools such as technological mining systems based on big data, machine learning, and natural language processing will automatically discover, explore, and predict users' interests and preferences, thereby realizing connections and recommendations of personalized information. These tools can deliver the desired precision information services to different types of farmers (e.g., plantation, cultivation, agricultural enterprises, and agricultural product dealers) according to their basic situations (geological positions and seasons for engaging in agricultural activities). This will become an important trend in rural networked services. Agricultural big data application services based on "Internet Plus" and sustainable agricultural big data business models and solutions will become an important industrial ecological system for modern agriculture to develop into a high-end market.

\section{References}

[1] Realization Conference of Robot Revolution. Japan's robot strategy [R]. Japan: Ministry of Economy, Trade and Industry, 2015.
[2] Fang L M. The Foton Lovol Apos released an intelligent agricultural solution [J]. Agricultural Machinery Market, 2016 (11): 54. Chinese.

[3] Mao Y, Wang K, Tang C G, et al. Application of internet of things technology in modern agriculture at home and abroad [J]. Jiangsu Agricultural Sciences, 2016, 44(4): 412-414. Chinese.

[4] Erickson B, David A W. 2015 precision agricultural services dealership survey results [R]. West Lafayette: Purdue University, 2015.

[5] Kong F T, Zhu M S, Han S Q, et al. A comparative study of agricultural informatization at home and abroad [J]. World Agriculture, 2016 (10): 10-18. Chinese.

[6] Yuan M, Chen Z Q, Yin C B, et al. The characteristics and system practice of the family farm in Germany: The perspective of sustainable utilization of cultivated land [J]. World Agriculture, 2017(11): 16-20. Chinese.

[7] Paustian M, Theuvsen L. Adoption of precision agriculture technologies by German crop farmers [J]. Precision Agriculture, 2017, 18(5): 701-716.

[8] Nagasaka Y, Umeda N, Kanetai Y, et al. Autonomous guidance for rice transplanting using global positioning and gyroscopes $[\mathrm{J}]$. Computer and Electronics in Agriculture, 2004, 43(3): 223-234.

[9] Noguchi N. Monitoring of wheat growth status and mapping of wheat yield's within-field spatial variations using color images acquired from UAV-camera system [J]. Remote Sensing, 2017, 9(3): 289.

[10] How to achieve the "Internet plus agriculture" in foreign countries [J]. Agriculture Engineering Technology, 2016 (3): 29-31. Chinese.

[11] Su C. The development of electronic agriculture in India and revelation to China "Internet Plus" agriculture [J]. Rural Economy, 2016 (11): 82-86. Chinese.

[12] Gandhi V P, Mei F. A decision-oriented market information system for forest and agro-forest products in India [J]. Iima Working Papers, 2002, 39(11): 1246-1253.

[13] Zhang Z G, Lv Q G, Zhang X J, et al. The Agriculture internet of things application in cotton industry in Xinjiang-example of 150 regiment in agriculture eight division $[\mathrm{J}]$. Xinjiang Agricultural Mechanization, 2015 (1): 28-33. Chinese.

[14] Tianjin Da Shun International Flower Co., Ltd.. "Internet Plus" modern agricultural power Da shun flower industry transformation [J]. Agriculture Engineering Technology, 2016 (30): 25-26. Chinese.

[15] Huang Y Y, Er X, Yang F, et al. Research on integration of internet of things system and security early warning in aquaculture [J]. Computer Technology and Development, 2017, 27(9): 201-204. Chinese.

[16] Xiong B H, Yang Z G, Yang L, et al. Research progress on the application of internet of things in animal husbandry in China [J] Transactions of the Chinese Society of Agricultural Engineering, 2015, 31(s1): 237-246. Chinese.

[17] Mao L, Cheng T, Cheng W L, et al. Construction and application of intelligent terminal system for agricultural product quality and safety traceability [J]. Jiangsu Journal of Agricultural Sciences, 2014, 30(1): 205-211. Chinese.

[18] Wu W Q, Li Z X. Research on the problem and mode innovation of the electric business development of fresh agricultural products in China [J]. World Agriculture, 2017 (6): 213-217. Chinese. 